\title{
The Process of Learning Revisited
}

Jan Böhm*

\begin{abstract}
The phenomenon of learning can be looked at from different perspectives. Besides its general everyday understanding, educational studies involve additional perspectives, such as behavioural, cognitivist, constructivist and possibly even humanistic approaches. Looking at learning from a pedagogical point of view rarely happens. This is all the more remarkable, as learning is surely a pre-condition of any pedagogical effort. The so-called "classical" learning theories are genuinely "foreign," as they are imports from other sciences, notably psychology. The learning aspect represented here results out of learning itself and focuses on the logical dimensions of this phenomenon. An attempt is made to track down the phenomenon of pedagogic learning with the aim of extending the diversity of perspectives to enable learning to be scientifically regarded.
\end{abstract}

Key words: pedagogical learning theories, learning as re-learning, learning and practice, social learning, subject-scientific learning theory, phenomenological learning

\section{Introduction}

All educational activities have an inescapable basic requirement which is scarcely touched on or reflected. Planning and setting up a lesson unit, didactic models, selection and application of methods and social settings, performance metrics and individual teaching support - all assume that schoolchildren are able to learn. Without this, any pedagogical endeavour would be meaningless. Educators build on people's learning capacities - a fundamental anthropological constant.

Children have already learnt a huge amount long before they go to school or kindergarten. One can assume that children entering a place of education already know how to learn. It may sound strange, but this is exactly what causes problems pedagogically. How can one optimise learning in a highly structured, professional setting?

This may seem somewhat technical, but is practised daily in all educational institutions. As long as this routine of learning works effectively, there is no reason to question it; this only occurs when the expected learning process peters out or fails. The reasons for this are diverse: no motivation, no interest in the subject, low concentration (at this moment), external worries or the learning content is not understood. This last point is the starting point for the following considerations. What happens if something is just not understood? We have all experienced this first-hand. Our "body" is included in the learning process. We experience a physical reaction when we have not understood something, although everybody else has got it, and we do not understand why we do not get it. We feel uncomfortable, embarrassed and humiliated, especially in front of others. Unfortunately, it is not unusual for a student to go through oral control in front of the whole class, causing anxiety, which frequently leads to failure.

* University of Education Upper Austria, Austria 
Beside the negative and often lifelong traumatic effects, these experiences can also be an opener for reflection and serve as a starting point for thinking about one's own learning. To find out why you failed, although you may belong to fast learners, you have to find out how learning works or rather how the learning operation works. The term pedagogical perspective has been chosen deliberately to separate it from other approaches, as this issue deals with the demarcation of the psychological concept of learning, where learning is seen as a linear and cumulative process of progression.

In contrast to psychological or bio-scientific learning concepts (relatively popular currently, as they conceive the phenomenon of learning as a more or less simplistic, mechanically-associative neutron reinforcement; thereby inadmissibly limiting learning to its materialistic side), pedagogic learning theory is concerned with the relationship between people and the environment. This interplay forges identity and advances personal maturity, or, to use an old-fashioned term - wisdom. The twoway process leads to a win-win situation. The individual develops within the environment and simultaneously, the world order changes.

To return to the initial problem: a learner does not understand the situation presented. The learner tries hard to grasp the concept offered and wants to understand, but (still) does not succeed. Why does the child fail to understand? The abovementioned approaches are of little use: it has nothing to do with a lack of motivation or insufficient incentives. It is not about incorrect information support, design flaws or even connective problems. To try, nevertheless, to find a scientific explanation of this phenomenon, four educational learning concepts are presented briefly.

\section{Theoretical Approaches}

\section{Expansive Learning}

Generally, the phenomenon of learning is considered from the outside. The pupil or the learning subject often appears not to operate or learn as expected. However, one can understand the phenomenon of learning from a different perspective, which is obviously closer to the actual problem: the learning subject itself.

The psychologist, Klaus Holzkamp (1993) undertook such a shift in perspective, changing from an outside perspective to a subjective perspective, the aptly called subject- scientific learning theory. He understands learning from the point of view of the learner. He writes: "Using this point of view, I am not neutral in the world as I relate to it as a sensual-physical, needy and interested subject" (p.21)

These given conditions turn the learner into an active, engaging in the world actor. Here the learner is aware of the correlations between their own living conditions and the social framework conditions they are embedded in. This suggests that negotiations between the subject and the environment are not per se harmonious, but rather the ones that must constantly be interpreted afresh and re-negotiated. A certain "adaptive fit" can be reached, but is never constant as individual living conditions as well as societal framework conditions are permanently in flux (although not always evenly or uniformly).

Human learning can help to offset this permanent and long-term "non-adaptation". This also means that learning opportunities can never be initiated only out of external factors, but always through inter-dependence between subject and environment. The "outside" does not impact directly, but becomes internalised through our perception and interpretation (and so tuned to our own needs). Only when this matching process runs into resistance, does it lead to "learning actions". "Learning actions" mean that the subject and not the object is the driving force. In other words, initiated from outside and seen purely as a 
reaction. Holzkamp (1993) says: "Human actions/sensitivities are neither merely immediately and externally conditioned nor are they only the result of mere subjective meaningfulness, but rather by the circumstances of our lives and times" (p.79).

People develop perspectives and interests from their point of view. Possible actions are therefore linked to the individual life interests. People explore the world around them within the horizon of their actual possibilities and opportunities. These actions acquire a significance through "active access to the world in which an individual actually creates and expands their life conditions." (Faulstich, 2013, p.81)

Going back to the original thesis that learning is initiated by an adaptive problem between the subject and the environment, this can be formulated as follows: learning opportunities are personal know-how gaps which do not allow a 'carry on as usual.' Previous interpretations and heuristics fail and have to be changed or extended through learning (re-learning). One could say, the discrepancies between available and still unavailable competences become visible and tangible.

As long as our life interests are not hindered and we can deal with our world, no learning processes are needed and we "seize" the world through the so-called coping actions. If, however, this fails, a learning loop must be inserted, which means I must change or adapt my previously tried and trusted coping strategies. According to Holzkamp (1993), this can be done either deliberately and target-oriented or unconsciously or incidentally. He also distinguishes between two forms of learning: defensive learning and offensive learning. These forms describe the handling of learning problems.

In general one can say:

- Defensive Learning means that learning is carried out to avoid foreseeable and negative consequences. For example, a bout of frenzied learning so as not to fail the set homework.

- Offensive Learning, on the other hand, means that learning opens up the world. In this process a foreseeable negative consequence should not be avoided, but seen as an extension of possibilities.

When learning becomes conscious and intentional, reasons can usually be found. These are closely linked with the interests, values and wishes of the learner. Important for learning choices is the personal value placed on the available alternatives and the degree of self-control over the decision. Regarding defensive learning, this is generally very low as opposed to offensive learning.

The emotive-motivational component of learning is clearly visible. Learning cannot only be reduced to its cognitive aspects, as is the case with many "classical" learning theories. Deci and Ryan could prove that learning performance rises significantly when a higher degree of self-determination and self-explanatory patterns are present (1993, p. 220). Peter Faulstich (2013) pulls these findings together, using the expansive mode of learning: "only when learning topics are communicated with the life interests of the individual, can expansive learning take place. The wider the learner's choices about objectives and actions, the greater the degree of self-determined action in learning. Expansive learning demands control over intentions, subject matter and methods of one's learning" (p.85). The pedagogic consequence of this assumption is evident: the increasing room for manoeuvring and choice, further motivation and a sense of autonomy. In other words, this means a radical criticism of the so-called learningteaching short circuits or the assumption that teaching (instruction) directly results in the expected performance. However, Holzkamp (1996) writes that, on the contrary, the insight must prevail, "(...) the concept that one can plan processes through syllabi, learning strategies, didactic equipment and thus create conditions under which the said person has no choice but to learn in the desired way, is pure fiction" (p.23). In reality this arrangement made over the heads of those affected creates resistance, refusal and evasion. Holzkamp suggests a solution to this problem: "In order to escape this dilemma, it is first necessary to create 
working conditions and forms of communication within which genuine learning interest can be systematically expressed and taken into account" (ibid., p. 24).

\section{Learning as re-learning}

Holzkamp stated that the starting point of effective learning was resistance to the implementation of habitual strategies to cope with life. Klaus Prange and Konstantin Mitgusch have tried to pinpoint this resistance phenonomically and so make it pedagogically valuable. Their starting point is human experience or, to be more accurate, they speak about experiencing rather than experience, as they stress process-relatedness rather than insularity which the term 'experience' suggests.

Even Aristotle concerned himself with experience and emphasised two specific moments: prior knowledge and the path of experience. Aristotle said that in all human experience there is a moment of generalness, so we are able to move from individual experience to classes of experience and then to general principles. Without this stored prior knowledge there can be no experience. By practising these experiences we gain knowledge of this generalness. The logical structure of transition from individual experience to classification and general principles has rightfully been criticised (see Mitgusch et al., 2008, p. 267). Our daily experience teaches us that this linearly ascending development cannot be generalised, as during this process disruptions or even blockages can occur.

Let us go back a step: what exactly happens during the advance of individual experience towards classification? Our prior experience anticipates a new situation, so it could also be said that this is guided by previous experience (see Mitgusch et al., 2008, p. 268). This anticipation also functions in new situations that are similar in structure to previous experiences. If they do not do so, a disruption occurs and normal actions cannot be continued successfully.

Exactly this negative point is a productive moment. Superficially, a learning loop is put in as suggested by Holzkamp, in order to overcome this obstacle. The action is corrected and the chain of experience can now be carried on. This is certainly true, but it does not get to the heart of the matter. It is not just superficial correction of an error, but getting extended knowledge of the already gathered knowledge or its relativity. "Only through this type of negation can the learner learn about the relativity of their knowledge, their experience and ultimately about themselves. The negation turns into something positive" (Mitgusch et al., 2008, p, 269).

The pedagogue Günther Buck (1989) takes this idea on board and transfers it to learning as a pedagogic phenomenon. Firstly, he distinguishes between three learning forms: being acquainted with, learning something new and relearning. According to Buck, being acquainted with something has no consequences for the learner and learning something new is merely adding knowledge, as already stated. Relearning is real learning. Here there is a break with the usual pattern of prior knowledge. In relearning, previous knowledge is not sufficient, our sense of anticipation is insecure and the learner is aware that the previous experience is not enough for this new challenge. S/He must solve this problem, but simultaneously recognises the structure of the learning process; not only does the learner solve the problem, but also s/he learns something about him/herself and his/her learning process. Buck (1989) writes: "Learning is not only an unbroken succession of inter-related acquisitions but, ideally, a relearning process. When someone says he has learnt something, s/he often means $s /$ he has relearnt something. However, relearning is not just a correction of ideas that have made about something; it is a change of attitude and thus the whole horizon of experience" (p. 47). Buck says that the learning quality of relearning can be seen in the way the negative experience of one's own anticipation creates a higher experience, this is the experience of becoming aware of oneself. This is such a new experience that it reflects the already learnt as a whole. 
Let us take 'prejudice' as an example. As 'pre' judices, they are neither negative nor positive. They are categories which give structure and orientation to our daily lives (see Gadamer, 1975). Every time a prejudice fails in practice, we change our prejudice, so we relearn. But we do not just adjust our prejudices, we learn for the first time that we have prejudices, that they structure our thinking and perceptions and that they are relative and can be reviewed.

\section{Learning through practice/exercises}

Practising at school is seen as a necessary duty, not as a potential pedagogic moment of opportunity. It is supposed to strengthen what has been painstakingly learnt. At least this is the common assumption. The regard that practice enjoys is shown by it being generally shifted to outside school hours; after all, practice can be done at home as no major pedagogic guidance is needed. School- initiated learning is methodically driven and is hardly content-accessible. This has consequences, as not the content is practised, but the method (see Prange, 1989). Practising in this perspective has a purely automotive, consolidating effect and cannot open up anything new. It is a means to an end.

It is the merit of educationalist Malte Brinkman (2008) that practice (he calls exercising the pedagogic form of practising) has been brought into educational discussion again. He rightly criticises the one-sidedness of exercises as "(...) a secondary learning form to secure results and grind in knowledge and ability instead of facilitating a new learning beginning and opening up horizons" (p. 278).

Reducing practice to its methodical aspects can be illustrated using Kippert's training book, much loved by teachers: Kippert (2006) reduces practising exercises to a mechanical training method. The mastery of the method is the goal. It is about the automation of skills and abilities. This view infers that things are repeated in the exact same form. However, this contradicts reality. Even with immense training of facts, these facts and the method of repetition changes. In these two aspects lies the pedagogic value of an exercise (Böhm, 2010). What then is reality regarding exercises? Brinkmann (see 2008, p.281) distinguishes three forms of exercises:

- $\quad$ The factual content acquisition (directed to the subject practised)

- $\quad$ The way of practising (technique-based practice)

- $\quad$ The reflexive relationship to practice (self-directed practice)

As we have seen in Klippert's example, the exercise is usually reduced to the first aspect, effectively giving away any pedagogic potential. In pedagogical practice, all three aspects are considered: facts, technique and self. Practice and exercises do not only target the subject being practised which should improve with repetition, nor just the appropriation of a practice technique, but also the learner him/herself, his/her views and attitudes as seen through his/her actions (ibid., p.281).

This last aspect seems to be especially important, but at the same time it clearly contradicts a reductionist notion of exercises: does not practice mean no longer having to think about the practiced exercise? If there is no interference in practising, the answer must be yes, but if this is exactly what happens, the answer must be no. This is the content link to the approach mentioned above: it is always the negative incident, the disturbance, the pausing from time to time which initiates conscious reflection. Here we are dealing with the negativity of practising.

Practice always includes the possibility of failure. In this case, practice was probably continued until the mistakes were rectified and in the transition from doing things badly to the mastery of the subject lies the educational value. The French phenomenologist Merleau-Ponty (1966) sees the 'world resistiveness' as the key to an opening up of the subject. This resistance forces us to reflect on and change our attitudes, interpretations and strategies. To overcome this resistance demands effort, 
patience and concentration. These attributes make exercises using "classical" techniques so attractive, for example, in Christian spiritual exercises. The same applies to all contemplative forms of self-care. In all these forms the 'self' is the subject of practice. Educational exercises are, of course, somewhat more limited than this example, but pedagogic exercises also offer the possibility of a reflexive handling of self even if this is not explicitly sought. The time-related succession of the exercises is a prerequisite, so that the exercises are varied and never only repeated. Reviewing is a "(...) meaningful and productive materialisation of what is already known and has been accomplished. Unlike the phrase "practice, practice, practice" the practice is repeated but under different conditions and circumstances" (Brinkmann, 2008, p.283).

It should now be clear that pedagogic practice opens up the world both re-productively and pro-ductively. Exercises consolidate what has been learnt but can at the same time be a beginning of learning, if the practise technique and also oneself is addressed.

\section{Learning in relationships}

So far, the phenomenon of learning has been treated as an individual event; this seems crucial, as learning is not just the learning of knowledge, but it is also a process which contributes significantly to becoming oneself and shapes the subjectivity of each person. Hitherto, the social dimension of learning has been hidden. Although each person learns individually, they do not live in isolation, but are firmly anchored in a social framework. Socialisation research (see Tillmann, 2010) calls this connection an 'interdependency network', meaning that every human being is embedded in manifold social units. George Simmel called this "social circles" (see Simmel, 1992). It should be emphasised that the process of socialisation is a two-way process in which both sides change; there is never just a one-sided adaption to the other.

This is similar to learning which also takes place in such an inter-dependent network. The social dimension of learning plays a subordinate part, or no part at all, in psychological learning theories. Not surprisingly, a strong incentive for collective learning came from sociology. In 1986, the German sociologist Max Müller (1986), published his "Studies on the foundation of a sociological theory of learning". It is quite remarkable for a sociologist to develop his own learning theory, but, unfortunately, his approach to pedagogy was hardly accepted or well received.

For some time now, however, the social dimension has played a more prominent role in learning. Especially, the so-called relational approaches focus on the inter-personal perspective. Tobias Künkler (2011) dealt with the correlation between subjectivity and relationality in the learning process, in his dissertation "Learning in relation to others". For Künkler, relationality is, above all, a way of thinking in contrast rather than a thinking in substance." Relationships are not seen as subsequent connections between the already existing entities, but, on the contrary, it is assumed that these entities in their specific form only arise out of previous relationships" (ibid. p. 527). In other words and using knowledge as an example, knowledge does not come into contact with other types of already existing knowledge as it is acquired, but arises through contact and discussion with others. Human subjectivity also appears through relationships between several points of reference. Relational subjectivity as an auxiliary construction should be seen as a space opening up and is in constant flux (ibid. p 530). Subjectivity has always been intersubjectivity; it has always been immersed in and created by society. A pioneer in his field is, above all, George Herbert Mead (1973), who described the development of human identity using an interplay of "I" and "me". He sees subjectivity not as a process of maturity, but rather as a continuously updated result of relationships with others. This relationship to others precedes the relationship to oneself and to the world. The importance of others for our own learning is especially relevant: "learning from a relational viewpoint is permeated with the desire to learn for others, respectively, within a desired relational matrix. We learn for others and not just from, through and with. We want to be loved, sought after and valued or at least being respected by others is 
of importance to us. Our wish to enter into relationships with others evokes, prevents and structures learning processes (Künkler, 2011, p. 540). And he continues: Whether and what is learnt or not learnt, is crucially dependent on what is significant or not significant for others (ibid). The relationship to others and the role models they present should not be underestimated. The phrase 'learn for yourself, not for others' maybe should be revised.

\section{Tobias Künkler differentiated four learning aspects:}

1. Explicit learning: specific practices dedicated to learning something. This is concerned with the acquisition of knowledge or special abilities and skills, usually to solve specific problems (practising, training, memorising ...). Generally, these learning processes are realised consciously and purposefully.

2. Implicit learning: casual, not consciously realised, non-intentional learning. It arises, so to speak, as a by-product of explicit learning (i.e. repeatedly practicing an action or practical knowledge).

3. Formative learning: forming process of incorporating 'implicit knowing-how' and implicit 'knowing-that', respectively, the acquisition of a horizon of experience which is the result of experience, learning and relationships.

4. Transformative learning: refers to the process of transforming primary habit forms to secondary habit forms. It is about the structural transformation of the 'implicit knowing-how' as well as the 'implicit knowing-that'. For example, the consolidation of action, thinking, perception, judgement and evaluation schemes and patterns. By transformative learning the experience horizon itself is changed (see Künkler, 2011 p.526).

It is important to recognise that this distinction is analytical. In practice, learning is always a combination of the abovementioned aspects, albeit with different weighting. Singled out for us is the recognition that learning is not a solitary, purely individual matter, but always an activity within a social group. We place ourselves in an inter-play of self and world references.

\section{Outlook}

The described vignette can, theoretically, be illuminated out of various perspectives. Not atypical would be to ask what the teacher could improve, so that pupils show the desired learning effect. This view implies that the pupil is able and willing to learn and considers the pupil an object of the teacher's educational and didactic endeavours. Learning, and this can probably be confirmed by all educators, is not a linearly increasing accumulation of knowledge and skills, but, on the contrary, a highly sensitive and unpredictable search for knowledge. That does not make psychological learning less important or useless - it is not. But its explanatory power is limited. Psychological learning can and should accompany pedagogical theories of learning and thus contribute to an extended understanding of the learning process. Meanwhile, the learning theory approaches outlined above focus on the learning subjects i.e. the pupils. They ask what conditions must be met so that learning processes can be initiated and successfully completed.

\section{References}

Böhm, J. (2010). Pädagogische Valenzen schulspezifischen Geschehens im Umfeld des Unterrichts. Hamburg: Prolog-verlag.

Brinkmann, M. (2012). Pädagogische Übung: Praxis und Theorie einer elementaren Lernform. Paderborn: Schöningh. 
Brinkmann, M. (2008). Üben. Elementares Lernen. Überlegungen zur Phänomenologie, Theorie und Didaktik der pädagogischen Übung. In: Mitgusch, K., Sattler, E., Westphal, K., Breinbauer, I. M. (Hrsg.), 278-294. Dem Lernen auf der Spur. Die pädagogische Perspektive. Stuttgart: Klett-Cotta.

Buck, G. (1989). Lernen und Erfahrung. Zum Begriff der Didaktischen Induktion. Darmstadt: Wissenschaftliche Buchgesellschaft.

Deci, E. \& Ryan, R. (1993). Die Selbstbestimmungstheorie der Motivation und ihre Bedeutung für die Pädagogik. In: Z.f. Pädagogik, 223-238.

Faulstich, P. (2013). Menschliches Lernen. Eine kritisch-pragmatische Lerntheorie. Bielefeld: Transcript.

Gadamer, H.G. (1975). Wahrheit und Methode. Tübingen: Mohr.

Holzkamp, K. (1993). Lernen. Frankfurt am Main: Campus Verlag.

Klippert, H. (2006). Methoden - Training. Weinheim: Beltz..

Künkler, T. (2011). Lernen in Beziehung: Zum Verhältnis von Subjektivität und Relationalität in Lernprozessen. Münster. Bielefeld: Transcript.

Mead, G.H. (1973). Geist, Identität und Gesellschaft. Frankfurt am Main: Suhrkamp.

Merleau-Ponty, M. (1966). Phänomenologie der Wahrnehmung. Berlin: De Gruyter.

Mitgusch, K., Sattler, E., Westphal, K., Breinbauer, I.M. (Hrsg.)(2008). Dem Lernen auf der Spur. Die pädagogische Perspektive. Stuttgart: Klett-Cotta.

Müller, M. (1986). Kollektive Lernprozesse - Studien zur Grundlegung einer soziologischen Lerntheorie, Frankfurt am Main: Suhrkamp.

Prange, K. (1989). Pädagogische Erfahrung. Vorträge und Aufsätze zur Anthroposophie des Lernens. Weinheim.

Simmel, G. (1992). Soziologie. Untersuchungen über die Formen der Vergesellschaftung. Frankfurt am Main: Suhrkamp.

Tillmann, K.-J. (2010). Sozialisationstheorien. Eine Einführung in den Zusammenhang von Gesellschaft, Institution und Subjektwerdung. Reinbek bei Hamburg: Rowohlt-Taschenbuch. 